\title{
There is no magic in speaker policies: creating gender equality at brain stimulation conferences
}

\author{
Editorial II to the supplement from the 2 nd European Conference on brain stimulation in \\ psychiatry
}

\author{
Anna-Katharine Brem ${ }^{1,2} \cdot$ Soili M. Lehto ${ }^{3,4,5} \cdot$ Daniel Keeser $^{6,7} \cdot$ Frank Padberg $^{6}$
}

Published online: 20 November 2017

๑) Springer-Verlag GmbH Germany, part of Springer Nature 2017

Gender inequality in science is hotly debated, and this topic has been raised likewise in the brain stimulation community with regard to the unequal ratio of female and male speakers at conferences [1-4]. While this discussion represents only one symptom of a deeper lying problem [5, 6], it is an immediate result of a lack of women in editorial boards and conference committees. Becoming aware of and acknowledging a problem represents the first step of solving it [7]. Awareness can be raised by observing and sharing observations with others. Subsequent steps involve evaluation of the problem, development of solutions, taking action, and repetition of these steps until resolution.

Gender balance is integral to innovation and scientific progress: a progress which is similarly mirrored in the world of business, where female representation on boards of

Anna-Katharine Brem

anna-katharine_brem@psych.mpg.de

1 Max Planck Institute of Psychiatry, Kraepelinstrasse 2-10, 80804 Munich, Germany

2 Division of Interventional Cognitive Neurology, Department of Neurology, Berenson-Allen Center for Noninvasive Brain Stimulation, Beth Israel Deaconess Medical Center, Harvard Medical School, Boston, MA, USA

3 Department of Psychology and Logopedics and Department of Psychiatry, Faculty of Medicine, University of Helsinki, Helsinki, Finland

4 Institute of Clinical Medicine/Psychiatry, University of Eastern Finland, Kuopio, Finland

5 Department of Psychiatry, Kuopio University Hospital, Kuopio, Finland

6 Department of Psychiatry and Psychotherapy, Ludwig-Maximilian University, Munich, Germany

7 Department of Radiology, Ludwig-Maximilians-University, Munich, Germany companies that focus on innovation is associated with higher success [8]. Gender balance based on scientific merit implies fairness, and encourages young female researchers. It is clear that we need to make an effort in order to reduce imbalance.

A significant action to promote gender equality in our field involved building a database for female brain stimulation researchers (www.womeninbrainstim.com), an effort recently initiated by K. Hoy, Melbourne, Australia. Over 160 female researchers have already registered at this website, which can be used to find conference speakers, as well as suitable candidates for conference committees and editorial and advisory boards. There is no magic in reaching gender balance among conference speakers. The introduction of a simple measure such as a speaker policy can have a substantial impact. Speaker invitations should be based on scientific merit on the one hand and, on the other hand, should contribute to the scientific profile of young researchers [3].

To promote gender balance, we can learn from others. Following previous suggestions from other scientific communities that faced similar issues [9], we developed a speaker policy and introduced a gender score (www.brainstimulation.eu/program/), both of which were placed prominently on the conference website. Eventually we achieved $40 \%$ female speaker participation at the $2^{\text {nd }}$ ECBSP, just by paying attention to gender balance. Many young female researchers participated in the conference and all three poster prizes were won by women. To further raise awareness, we presented our action at the conference opening and in the form of this editorial. We can moreover learn from the Society for NeuroEconomics, which implemented few but vital ideas (C. M. Kuhnen and B. Knutson, personal communication). For example, as they noticed that women submitting their work were less likely to opt-in for a talk when given the choice between poster and oral presentation, they made it the default that whoever submitted an abstract to the 
conference would be willing to present their work in a plenary session. This leaves it up to the conference committee to decide whose work should be presented orally. Furthermore, when constructing the slate for new board members, they make sure to have representative numbers of men and women on the list of candidates.

A number of actions to reduce gender bias have been suggested $[9,10]$ and were even examined scientifically, such as "scientific diversity interventions" designed for science faculty members [11]. However, the implementation of these suggestions has not really taken off on a broad scale yet. Responsibility for action lies with faculty members, sponsors, conference organizers, government agencies, journals, and editorial boards. Importantly, the key to success lies in the readiness of both women and men to contribute to this goal. Men have started to take the pledge (i.e., "men say no to all-male-panels") in various fields (www.owen.org/ pledge; www.manpanels.org/; http://tackanej.se/men-say-nothanks/). Both men and women should ask about the gender diversity of panels in which they are invited to participate, and hereby contribute to positive change.

Finally, our website (www.brain-stimulation.eu/contact/) can still be used for personal or anonymous feedback on this issue. With our action for the $2^{\text {nd }}$ ECBSP, we wanted to make a clear statement that we actively advocate the promotion of gender equality, whilst taking into account excellent scientific qualifications of both sexes. We hope that we will encourage others to follow our example.

\section{References}

1. Antal A (2017) Letter to the editor: a late response from a female scientist to Hoy, "gender imbalance at brain stimulation conferences: we have a problem and it is Everyone's problem". Brain Stimul 10:855. 10.1016/j.brs.2017.03.004

2. George MS, Sackeim HA (2017) Response to Hoy, "gender imbalance at brain stimulation conferences: we have a problem and it is everyone's problem". Brain Stimul 10:157. 10.1016/j. brs.2016.10.011

3. Hinder MR, Fujiyama H, Vallence A-M (2017) Response to "response to hoy, 'gender imbalance and brain stimulation conferences: we have a problem and it is everyone's problem"'. Brain Stimul 10:158-159. 10.1016/j.brs.2016.11.014

4. Hoy K (2017) Gender imbalance at brain stimulation conferences: we have a problem and it is everyone's problem. Brain Stimul 10:155-156. 10.1016/j.brs.2016.10.007

5. Glass ceiling indexlthe economist. http://infographics.economist. com/2017/glass-ceiling/. Accessed 10 Nov 2017

6. Handley IM, Brown ER, Moss-Racusin CA, Smith JL (2015) Quality of evidence revealing subtle gender biases in science is in the eye of the beholder. Proc Natl Acad Sci USA 112:1320113206. 10.1073/pnas. 1510649112

7. Chachra D (2017) To reduce gender biases, acknowledge them. Nature News 548:373. 10.1038/548373a

8. Dezso C, Ross D (2011) Does female representation in top management improve firm performance? A panel data investigation. Social Science Research Network, Rochester, NY

9. Martin JL (2014) Ten simple rules to achieve conference speaker gender balance. PLoS Comput Biol 10:e1003903. https://doi. org/10.1371/journal.pcbi.1003903

10. (2015) Sexism has no place in science. Nature News 522:255. https://doi.org/10.1038/522255a

11. Moss-Racusin CA, van der Toorn J, Dovidio JF et al (2016) A "scientific diversity" intervention to reduce gender bias in a sample of life scientists. CBE Life Sci Educ. 10.1187/cbe.15-09-0187 